\title{
Mathematical Modelling of Performance and Wear Prediction of PDC Drill Bits: Impact of Bit Profile, Bit Hydraulic, and Rock Strength
}

\author{
Ahmed Z. Mazen ${ }^{1}$, Iqbal M. Mujtaba ${ }^{1}$, Ali Hassanpour ${ }^{2,}$ Nejat Rahmanian ${ }^{1, *}$ \\ ${ }^{1}$ Chemical Engineering Department, Faculty of Engineering and Informatics, University of Bradford, Bradford, \\ BD7 1DP \\ ${ }^{2}$ School of Chemical and Process Engineering, University of Leeds, Leeds, LS2 9JT \\ *Corresponding author: n.rahmanian@bradford.ac.uk
}

\begin{abstract}
The estimation of Polycrystalline Diamond Compact (PDC) cutters wear has been an area of concern for the drilling industry for years now. The cutter's wear has been measured practically by pulling the bit out for evaluation at the surface. It is important to find the right time for tripping out as this helps to avoid the fishing job and reduces the operational cost significantly. The prediction of the drilling performance is based on the interaction of cutter and rock. Several authors focused on the cutter-rock interface but only a few researchers tried to model the wear of the PDC bit cutters. The aim of this research is to understand the relationships between the rate of penetration (ROP) and the drilling variables per each foot, and then determine the overall bit efficiency for the whole drilling operation. A new mathematical model is derived to predict the PDC bit performance by considering the factors that were already not taken into account. These factors include rock strength, bit design, and bit hydraulic. The model investigates the effect of these parameters to estimate the abrasive cutters wear on the inner and the outer bit cones by deriving modified equations to calculate the mechanical specific energy (MSE), torque, and depth of cut (DOC) as a function of effective blades (EB). The model is used to forecast the bit cutters wear conditions in four wells in the oil fields located in Libya, which were drilled with three different PDC's sizes. The model enables the results to be compared to the actual bit cutters wear measured for inner and outer cones. The results are found that are well in agreement with the actual field data obtained in bit records.
\end{abstract}

\section{Keywords}

PDC cutters wear; Mechanical specific energy; Depth of cut; Effective blades; ROP. 


\section{Introduction}

Drill bits are the main tools that penetrate the formation down to the planned production zone. An efficient PDC bit should have good drillability by achieving a sufficient ROP, and it should be durable to be used in other wells. Both ROP and bit life rely directly on bit design, drilling parameters, and rock properties (Ersoy and Waller, 1995, Sinor and Warren, 1987).

Ziaja and Miska (1982) presented a mathematical model for the diamond core bit to estimate rock strength index, rock abrasiveness index, and ROP. The model also provided an equation to measure the bit dullness by assuming gradual bit wear while drilling.

Warren and Sinor (1987) developed a single PDC cutter model to predict the cutter temperature, force, and wear. The model assumed constant ROP and considered the mechanical design parameters, and results were compared to the laboratory drilling test for four different bits design.

Kuru and Wojtanowsicz (1988) proposed a model that derived from torque and ROP equations to prevent early damage of PDC bit by evaluating the bit condition and detecting the rock change while drilling. The approach required data from bit geometry and its dull condition to set up software to optimize the drilling parameters.

Understanding the breakage process generated at the cutter - rock interface is the key for interpretation of the drilling parameters. There are considerable work in the literature that focused on studying the cutter - rock interface but not to determine the PDC bit wear. Jones (1990) presented an improved cutter configuration to optimize the cutter- rock interface area according to the total volume of diamond that penetrate the formation along the bit radius. Detournay and Defourny (1992) studied the cutter- rock interaction as a function of two processes: cutting of the rock and the friction underneath the cutters. They developed a model, which was used as a guide to understand the drilling process by assuming that the cutting component of the torque and the weight on bit (WOB) are both proportional to the depth of cut (DOC).

Wojtanowicz and Kuru (1993 ) proposed a model to control the performance of a spherical PDC bit cutters in order to maintain the balance between the WOB distribution and bit wear uniformity. The results were obtained by adjusting empirical constants while drilling in homogenous formation to match bit recorded data from offset well. The model assumed that WOB, rotary speed (RPM), mud flow are constant and the model also ignored the cutting angle. 
Gerbaud et al. (2006) developed a new cutter-rock interface by taking into account the latest technology of the PDC cutters shape and investigated its effects on the ROP, bit stability, and bit wear. Detournay et al. (2008) presented a model to extend their work of 1992. The model introduced the contact length, a measure of bit dullness, and the contact strength to the frictional process. The model was developed under the same assumption that the drilling response of PDC bit followed a linear constraint between torque, WOB, and DOC.

Tulu and Heasley (2009) investigated numerically a 3D single cutter to analyse the cutter-rock interaction and compared their work with a single cutter on a laboratory scale. The objective of their work was to analyse the vertical and horizontal forces based on the cutting depth, however, they ignored the effect of mud hydraulic. Gouda et al. (2011) developed a mathematical model to estimate the PDC cutters wear by including the torque obtained from drill pipe, string stabilizer, and the bit. The model was valid for certain back and side rack angles.

Yahiaoui et al. (2011) studied the cutter-rock interaction, by testing six different manufacturers' cutters in the laboratory scale to compare the wear rate. The tests were carried out under atmospheric conditions in which no drilling fluid was pumped into the contact surface. Patil and Teodoriu (2013) studied the cutter-rock interaction and introduced a mathematical model to analyse the stick-slip vibration (Alkaragoolee, 2018) by considering the PDC cutter wear.

Liu et al. (2014) introduced an analytical model coupled with real-time gamma-ray data to predict the PDC bit wear. The model assumed that the volume loss of cutters is proportional to WOB. Chen et al. (2014) presented a new cutter-rock interaction to analyse the cutting force. They concluded that the cutting arc length plays a major role in the cutting force calculation. Doshvarpassand et al. (2017) conducted the experimental work to evaluate the effects of cutterrock interaction on the cutting action of different sizes of PDC cutters. They found that the effect of the cutters edge may differ based on the rock type.

Micro- and nano-scratch tests wear applied to estimate the wear volume of the PDC cutters diamond layers. The experimental results were compared to the results obtained from wear models in the past (Abbas and Hassanpour, 2018).

Yang et al. (2019) presented a model as a combination of mechanical specific energy, principal component analysis, and wavelet analysis to decide when to pull the bit out of the hole and 
predict cutters wear of the Kymera PDC bit. The model suggested a constant wear increment with the depth.

To evaluate the bit performance accurately, the bit profile needs to be considered along with the cutter-rock interface. This has been proved by Glowka (1987) who developed a method to predict the cutter force and bit performance. He confirmed that the bit profile can significantly affect PDC wear. His model was based on the assumption that cutter wear will be uniform regardless of its location.

A number of researches aimed to design the crown shape of the PDC bit by employing the principles of equal wear, equal volume of rock removed and power (Glowka, 1985, Hibbs and Flom, 1978). However, they ignored the effect of cutter-rock interaction; therefore, they did not efficiently reflect the force and the cutting wear. Wang et al. (2018) studied the cutter-rock interaction and concluded that the bottom hole shape of the PDC bit is one of the essential factors that affect the force and the wear of PDC cutters.

Most of the available models in the literature are not so efficient, albeit are helpful, as they do not address the real operating conditions of the rig site. These models were developed using a laboratory scale and under atmospheric conditions. This paper proposes a new model that can be applied on rig site and it is a function of all drilling parameters that include the rock-bit interaction, bit profile, rock strength, and bit hydraulic as shown in (Fig.1). The results enable the model to compare the cutters wear on both inner and outer cones with the actual bit wear according to the standard bit record form. Full description of the analyses of the drilling parameters is given by adjusting some factors for rock hardness and mud hydraulic, rock friction, and DOC to understand prediction of the bit performance.

Fig.1 PDC cutters wear prediction model.

\subsection{Computational Model of PDC Bit Life}

The design of the PDC profile was based on the assumption of equal wear and equal volume and energy (Wang et al., 2018). However, the distribution and density of cutters along the bit profile are not the same. Therefore, the degree of wear is not the same for inner and outer cutters due to the rotating radius. In this work, bit profile is considered and the analyses are divided into inner and outer cones. 
The force applied on PDC is transferred to all cutters, and the cutter breaking mechanism differs because of bit design and cutters location, therefore, the analyses of the forces on the single cutter as proposed in previous work done by Glowka (1985), Hibbs and Flom (1978) is not accurate. Huang et al. (2017) added that the force conditions are more related to cutting arc length and wear degree. In this model, the drilling impedance (DRIMP) as a wear evaluation index will be used instead of using cutting forces.

The previous studies (Gouda et al., 2011, Pryhorovska, 2017, Wojtanowicz and Kuru, 1993) carried out on the analysis of rock-bit interaction suggested good hole cleaning. Besides, Kuru (1990) confirmed that the diamond compact material loses strength at a temperature above $350^{\circ} \mathrm{C}$ resulting from high friction generated at the interface. Therefore, drilling fluid has to be pumped in during drilling operations to maintain and keep the operation temperature below $350^{\circ} \mathrm{C}$. Additionally, it was shown experimentally that the wear rate of PDC cutter was much greater for dry shearing than wet cutting (Gray, 1967). Hence, to address the real conditions of the drilling operation, this model considers the influence of the bit hydraulic.

It has been confirmed that abrasive wear is a function of DOC; therefore, to control DOC of PDC cutters, the volume of rock removed and the torque generated have to be controlled (Sinor et al., 2001). DOC is modified in this work based on the active cutters for both cones.

Tian et al. (2015) concluded that the drilling efficiency and the volume wear rate of PDC bit is dependent on the cutting angle, while Hankins et al. (2015) proved that the back and side rack angles have the minor effect on the performance of drilling. As a result, this model ignores the effect of back and side - rack angles and consider the cutting angle.

Hareland and Rampersad (1994), Maurer (1966), and Teale (1965) used Eq. 1 which gives the theoretical volume of the removed rock per revolution.

$\left(V_{r}\right)_{t}=\frac{T}{M S E}=2 \pi \sum_{i=n}^{i} A_{C} \times R$

Where $\left(\mathrm{V}_{\mathrm{r}}\right)_{t}$ is the theoretical volume of removed rock $\left(\mathrm{in}^{3}\right)$, $\mathrm{T}$ is the torque $\left(\mathrm{lb}_{\mathrm{m}}-\mathrm{in}\right), \mathrm{MSE}$ is the mechanical specific energy (psi), $\mathrm{A}_{\mathrm{C}}$ is the cutting area of the cutter $\left(\mathrm{in}^{2}\right)$, and $\mathrm{R}$ is the radial or the distance from cutter to bit centre (in).

MSE is defined as the ratio between the input energy to the volume of removed rock. One of the major causes of error for this method in estimating the MSE is that the rock hardness is not considered because of the variety of rock strength (Tveit and Berg, 2016). Apart from the 
energy needed to crush the rock, the energy which is required to transport the drilling cuts underneath the PDC bit to the surface should be considered as well (Mohan et al., 2009).

In this work, MSE is correlated with rock hardness and mud hydraulic as shown in Eq. 2.

$\mathrm{MSE}_{\text {mod. }}=\mathrm{MSE}_{\mathrm{R}}+\mathrm{MSE}_{\mathrm{H}}$

The modified MSE for rock hardness is presented in Eq. 3 as follows:

$\mathrm{MSE}_{\mathrm{R}}=\mathrm{MSE} \times$ Hardness Ceofficient

Where, $\mathrm{MSE}_{\text {mod. }}$ is the modified mechanical specific energy (psi), $\mathrm{MSE}_{\mathrm{R}}$ is the correlated mechanical specific energy for the rock hardness (psi), and $\mathrm{MSE}_{\mathrm{H}}$ is the correlated mechanical specific energy for the mud hydraulic (psi).

Hardness Ceofficient $=\frac{\text { MSE }}{\text { Hardness }}$

Jogi and Zoeller (1995) proposed that the rock hardness can be estimated by use of Eq. 5 .

Hardness $=\frac{\mathrm{WOB} \times \mathrm{RPM}}{\operatorname{ROP} \times \mathrm{D}_{\mathrm{b}}}$

Where, Hardness (psi), WOB is the weight on bit $\left(\mathrm{lb}_{m}\right)$, RPM is the rotary speed (rpm), ROP is the rate of penetration ( $\mathrm{ft} / \mathrm{hr}$ ), and $\mathrm{D}_{\mathrm{b}}$ is the bit diameter (in).

Kerr (1988) introduced that the specific hydraulic energy can be expressed by the hydraulic horsepower efficiency as follows:

$\mathrm{MSE}_{\mathrm{H}}=\mathrm{HSI}=\frac{\mathrm{HP}}{\mathrm{D}_{\mathrm{b}}{ }^{2}}$

Where, HSI is the bit hydraulic efficiency (psi), HP is the bit hydraulic horsepower (lb).

HP and the bit pressure drop (P) can be estimated by applying Eqs. 7 and 8 as proposed by Kerr (1988).

$\mathrm{HP}=\frac{\mathrm{P} \times \mathrm{Q}}{1714}$

Where, $\mathrm{P}$ is the bit pressure drop (psi), and $\mathrm{Q}$ is the flow rate (gpm).

$\mathrm{P}=\frac{\mathrm{Q}^{2} \times \mathrm{MW}}{\mathrm{TFA}^{2}}$

Where, MW is the mud weight (lb/gal), and TFA is the bit total flow area $\left(\mathrm{in}^{2}\right)$.

The torque also is correlated with rock friction in this work as stated by Jogi and Zoeller (1995).

The modified torque is given in Eq. 9. 
$\mathrm{T}_{\text {mod. }}=\mathrm{T} \times \mu$

Where, $\mathrm{T}_{\text {mod. }}$ is the modified torque $\left(\mathrm{lb}_{\mathrm{m}}-\mathrm{in}\right)$, and $\mu$ is the rock friction (unitless).

$$
\mu=\frac{T}{\operatorname{WOB} \times D_{b}}
$$

By rearranging and substituting the parameters, Eq. 1 become:

$\frac{\text { Hardness } \times \mathrm{T}}{\operatorname{MSE} \times W O B \times D_{b}} \times\left(V_{r}\right)_{a}=2 \pi \sum_{i=n}^{i} A_{C} \times R$

$\frac{\text { Hardness } \times \mathrm{T} \times \mathrm{D}_{\mathrm{b}}}{\text { MSE } \times \text { DRIMP }}=8 \sum_{\mathrm{i}=\mathrm{n}}^{\mathrm{i}} \mathrm{A}_{\mathrm{C}} \times \mathrm{R}$

Where, DRIMP is the wear evaluation index (lb/in).

The actual volume of removed rock as a function of ROP can be defined as reported by Jogi and Zoeller (1995) in Eq. 13.

$\left(V_{r}\right)_{a}=\frac{\pi D_{b}^{2}}{4} \times \frac{R O P}{R P M}$

Where, $\left(\mathrm{V}_{\mathrm{r}}\right)_{\mathrm{a}}$ is the actual volume of rock removed per revolution $\left(\mathrm{in}^{3}\right)$.

DRIMP can be estimated using Eq. 14 as proposed by De Reynal (2011).

DRIMP $=\frac{\text { WOB }}{\text { DOC }}$

Where, DOC is the depth of cut (in).

Sinor et al. (2001) defined the depth of cut per revolution as a function of ROP and RPM as stated in Eq. 15.

$\mathrm{DOC}=\frac{\mathrm{ROP}}{\mathrm{RPM}}$

Chen et al. (2014) modified Eq. 15 by including the number of blades as follows.

$\mathrm{DOC}=\frac{\mathrm{ROP}}{\mathrm{RPM} \times \mathrm{N}_{\mathrm{b}}}$

Where, $\mathrm{N}_{\mathrm{b}}$ is the number of blades.

The PDC bit is designed with a plurality of cutters mounted on every blade. Once weight applied on the bit and the bit started rotating, the cutter dragged by torque to cut a layer of rock. Based on that, DOC is the depth to which cutter penetrates the formation as shown in Fig. 2. In this work, DOC is calculated based on a modified method suggested in Spread (2017) (see Eq. 17). The objective of this technique is to estimate the effective blade (EB) which is defined as 
how partially the cutters are involved in the drilling mechanism by computing the active cutters width to the blade length at a given ROP. Then DOC is calculated for the inner and outer cones using Eq. 17.

$\mathrm{DOC}=\frac{\mathrm{ROP}}{\mathrm{RPM} \times \mathrm{N}_{\mathrm{b}} \times \mathrm{EB}}$

Where, EB is the effective blades (unitless).

Fig.2 Diagram of PDC drill bit cutting element $D_{C}, D O C, A_{C}, r_{o}, r_{i}, C_{t}$, and $C$.

EB can be calculated using Eq. 18 as a function of the total cutters' width on the blade $\left(\mathrm{C}_{\mathrm{t}}\right)$ in both cones (see Fig. 2).

$\mathrm{EB}=\frac{\mathrm{C}_{\mathrm{t}}}{\mathrm{L}_{\mathrm{b}}}$

Where, $C_{t}$ is the total of cutters width (in), and $L_{b}$ is the blade length (in).

$\mathrm{L}_{\mathrm{b}}$ can be determined according to the bit design as seen in Fig. 3. The cone height $(\mathrm{G})$ is determined as shown in Fig. 3.

Fig.3 Updated bit selection chart (Bourgoyne et al., 1986).

The inner and outer radius as shown in Fig. 4 can be determined using Eqs. 19 and 20:

$r_{i}=\frac{2}{3} \times r_{b}$

$\mathrm{r}_{\mathrm{o}}=\frac{1}{3} \times \mathrm{r}_{\mathrm{b}}$

Where, $r_{b}$ is the bit radius (in), $r_{i}$ is the inner cone radius (in), and $r_{o}$ is the outer cone radius (in).

Then, $L_{b}$ can be calculated in both cones using Eqs. 21 and 22 as shown in Fig. 4.

$$
\begin{aligned}
& \mathrm{L}_{\mathrm{b}}(\text { inner })=\left[\left(\mathrm{r}_{\mathrm{i}}\right)^{2}+(\mathrm{G})^{2}\right]^{0.5} \\
& \mathrm{~L}_{\mathrm{b}}(\text { outer })=\left[\left(\mathrm{r}_{\mathrm{o}}\right)^{2}+(\mathrm{G})^{2}\right]^{0.5}
\end{aligned}
$$

Fig.4 Inner and Outer Cones (Brandon et al., 1992). 
The cross-sectional area of the cutting $\left(\mathrm{A}_{\mathrm{C}}\right)$ is dependent on the depth of cut and cutter arc length, taking into account the distribution of all cutters within the radial (Chen et al., 2014, Glowka, 1985).

Chen et al. (2014) stated that the arc length of cutters varies according to its location in the cone and the shape of the cutting area as shown in Fig. 5. Therefore, the cutting area in this model will be calculated as a function of cutter width (C) instead of arc cutter length $\left(A_{C}=\right.$ DOC $* C$ ) as described in Fig. 2 and Eq. 23.

Fig.5 Various cutters geometry due to different locations.

Gouda et al. (2011) reported that the cutting force is obtained as follows.

$\mathrm{F}_{\mathrm{c}}=\frac{\mathrm{A}_{\mathrm{C}}}{\cos \emptyset} \times \delta=\frac{\mathrm{DOC} \times \mathrm{C}}{\cos \varnothing} \times \delta$

Where, $\mathrm{F}_{\mathrm{c}}$ is the cutting force $(\mathrm{lb}), \emptyset$ is the cutting angle $\left(^{\circ}\right)$, and $\delta$ is the hardness or the cutting force per unit area (psi).

The cutter width can be calculated as suggested in Spread (2017) using Eq. 24.

$\mathrm{C}=2 \times\left[\mathrm{DOC} \times\left(\mathrm{D}_{\mathrm{C}}-\mathrm{DOC}\right)\right]^{0.5}$

Eq. 25 is developed based on Eq. 23 by including the number of cutters to compute DOC and $\mathrm{C}$ for inner and outer cones.

DOC $\times \mathrm{C} \times \mathrm{N}_{\mathrm{c}}=\frac{\text { WOB }}{\text { Hardness }} \times \cos \emptyset$

Where, $\mathrm{N}_{\mathrm{c}}$ is the number of cutters.

In the cutting process using PDC bit, the mechanism of the cutting element at the bottom hole is complex. To facilitate the analyses of the cutting forces, based on bit design, the cone height is assumed to be 3 inch for the 8.5" and 12.25" PDC bits, and 4 inches for the 16" PDC bit as follows:

- Both 8.5" PDC are designed with a parabolic profile with shallow cone. Therefore, the cone height value represents the option 6 as shown in Fig. 3, which is within the range of $1 / 8 D_{b}<G$

- 16" PDC is designed with a parabolic profile with a medium cone. Therefore, the cone height value represents option 5 as shown in Fig. 3, which is within the range of $1 / 8 D_{b}$ $<\mathrm{G} \leq 1 / 4 \mathrm{D}_{\mathrm{b}}$. 
- 12.25" PDC is designed with a parabolic profile with a medium cone. Therefore, the cone height value represents option 5 as shown in Fig. 3, which is within the range of $1 / 8 \mathrm{D}_{\mathrm{b}}<\mathrm{G} \leq 1 / 4 \mathrm{D}_{\mathrm{b}}$.

Knowing the value of $G$ and $L_{b}$, the cutting angle can be easily estimated. Given WOB, RPM, torque, $\mathrm{N}_{\mathrm{b}}$, and density of cutters in both cones; gPROMS software is used to numerically solve the model and find the cutter width C and DOC for both inner and outer cones by using Eqs. 24 and 25. Then, DOC is modified by the use of Eq. 17 .

It has been reported that the abrasive wear occurred caused by low DOC, while high DOC caused an impact wear (Van Quickelberghe et al., 2006). The wear occurs while the bit is rotating but not cutting (Mensa-Wilmot et al., 2003). This was confirmed by Gouda et al. (2011) who stated that no torque leads to wear. On this basis, this model neglects the cutting force on the wear effect and heat generated between the cutters - rock interaction to estimate the bit wear.

Maurer (1966) stated that Eq. 26 gives the energy of rotation per revolution:

Energy $_{\text {rot. }}=2 \pi \times \mathrm{T} \times \mathrm{RPM}$

The correlated MSE then is defined as follows in Eq. 27 which then be substituted in Eq. 12.

$\mathrm{MSE}=\frac{\text { Energy }_{\text {rot. }}}{\left(\mathrm{V}_{\mathrm{r}}\right)_{\mathrm{a}}}$

Maurer (1966) defined the torque due to friction as a function of the wear cutter area with zero cutting force as shown in Eqs. 28.

$\mathrm{T}=$ Cutting Force $+\mu \times \sigma^{\prime} \times \mathrm{D}_{\mathrm{b}} \times \mathrm{A}_{\mathrm{w}}$

Where, $A_{w}$ is the wear cutter area $\left(\mathrm{mm}^{2}\right)$.

In this work, $A_{w}$ is estimated based on what was proposed by Detournay (1993) as follows:

$A_{w}=L \times r_{c}$

Where, $r_{c}$ is the cutter radius $(\mathrm{mm})$, and $\mathrm{L}$ is the wear cutter height $(\mathrm{mm})$.

By substituting Eq. 29 into Eq. 28, a new Eq. 30 is obtained to calculate the torque as a function of $\mathrm{L}$.

$\mathrm{T}=2 \times \mu \times \sigma^{\prime} \times \mathrm{r}_{\mathrm{b}} \times \mathrm{r}_{\mathrm{c}} \times \mathrm{L}$

Finally, L can be estimated by taking into account the number of cutters on both inner and outer cones using Eqs. 26, 27, and 30. 
The overall methodology is shown in the flow chart in Fig. 6. The steps of the modeling process are as follows:

Step 1: A collection of the required data, and apply the model equations using Eqs. 17, 18, 24 and 25 to determine the cutter-rock contact variables on inner and outer cones.

Step 2: The volume of removed rock is estimated on both cones using Eq. 13 and rock strength is determined based on cutting percentage as described in section 1.4.

Step 3: DRIMP, MSE, and torque are calculated based on Eqs. 9, 12 and 14 in both cones to show the influence of bit forces on bit wear.

The model has been applied to four vertical wells in the oil fields of Libya. The candidate wells were drilled by using three different sizes of sharp PDC bits and one used PDC bit. The formation stress $\left(O^{\prime}\right)$ is estimated according to the cutting percentage of the lithology that was already provided in the well logging data (see section 1.4). The model equations are used to determine the PDC cutters wears by calculating the height of cutters wear using the analyses of the drilling parameters which determined as an average for every foot, then the estimated cutters wear is compared to the actual cutters wear obtained in the bit record.

Fig.6 Flow chart illustrating the proposed technique.

\subsection{Assumptions}

The following assumptions were made in this work to estimate the abrasive cutters wear:

- It is assumed all cutters that located in the inner cone have equal wear, equal volume, and energy (Wang et al., 2018). The same is also applied for the outer cone.

- DOC and cutting area $\mathrm{A}_{\mathrm{C}}$ were assumed constant for all cutters in every cone.

- The model considered the PDC cutters as round in shape as the most used shape.

- Blades have the same length and are assumed to be straight to calculate $L_{b}$ for both cones (see Fig.4, Eqs. 21, and 22). Also, the space between cutters is neglected.

- Radial location of cutters is equal to the average distance for both inner and outer. The inner radial $\left(\mathrm{R}_{\mathrm{i}}\right)$ is the distance between cutter position at the middle of the inner cone to the bit centre $\left(\frac{r_{i}}{2}\right)$, and the outer radial $\left(R_{0}\right)$ is the distance between cutter position at the outer cone middle to the bit centre $\left(\frac{r_{0}}{2}+r_{i}\right)$ as shown in Fig. 5. 


\subsection{Unconfined Compression Strength as a Measure of Formation Strength}

The model calculates the formation strength which is derived from the unconfined compressional strength (UCS) values as shown in Table 1 and the formation cutting percentage as shown in Figs. 7, 14, 22 and 27. The standard lithology column was broken down into sections where the formation strength is measured.

- The formation was divided into different sections as described and shown in Figs. 7, 14,22 and 27.

- The formation strength was estimated by multiplying the cutting fraction with the values of UCS shown in Table 1.

\begin{tabular}{|c|c|}
\hline Rock Type & UCS, MPa \\
\hline Sandstone & 70 \\
\hline Limestone & 25 \\
\hline Shale & 20 \\
\hline Calcilutite & 15 \\
\hline Anhydrite & 25 \\
\hline Clay & 2 \\
\hline Dolomite & 70 \\
\hline Salt & 12 \\
\hline Chert & 180 \\
\hline Marble & 100 \\
\hline
\end{tabular}

Table 1. UCS for various rocks (Ragan, 2009).

\section{Results and Discussions}

Based on the methodology described in the above sections, the results of analysis for the different wells of 1, 2, 3 and 4 are presented, in ranking order, in this part.

\subsection{Well Number 1}

The 8.5" PDC bit with 8 blades and $13 \mathrm{~mm}$ cutter size ran at $12720 \mathrm{ft}$ to $14343 \mathrm{ft}$ to drill through Lower Sirte, Upper salt, and Mid anhydrite, which mainly consist of shale, limestone, anhydrite, and salt (see Fig. 7). The bit is pulled out because there was a reduction in penetration rate (PR) and dulled in the bit record for 1-1 (a measure of bit ware- 1mm lost in inner and $1 \mathrm{~mm}$ lost in outer cone out of $8 \mathrm{~mm})$.

Fig.7 Estimation of the Lower Sirte formation strength. 
Table 2 summarizes the obtained average of ROP, UCS, DOC, EB, and DRIMP values. DRIMP in both cones which reflect the bit efficiency condition increase with UCS and decreases with ROP for Lower Sirte, Upper salt, and Mid anhydrite rocks. Fig. 8 shows the profiles of ROP, WOB, and RPM along the drilling depth obtained form well logging. The figure also correspondingly shows the trends of EB, DRIMP, and L that were calculated using the model. It can be seen from Fig. 8 that EB for both inner and outer cones is increased with ROP while WOB and DRIMP show an inverse proportional to ROP among the whole interval.

\begin{tabular}{|c|c|c|c|c|c|c|c|c|c|c|}
\hline \multirow[b]{2}{*}{$\begin{array}{l}\text { Rock } \\
\text { Type }\end{array}$} & \multirow[b]{2}{*}{$\begin{array}{c}\text { Thick, } \\
\text { ft }\end{array}$} & \multirow[b]{2}{*}{$\begin{array}{l}\text { UCS, } \\
\mathrm{MPa}\end{array}$} & \multirow[b]{2}{*}{$\begin{array}{c}\text { Time, } \\
\text { hr }\end{array}$} & \multirow[b]{2}{*}{$\begin{array}{l}\text { ROP, } \\
\mathrm{ft} / \mathrm{hr}\end{array}$} & \multicolumn{2}{|c|}{$\mathrm{DOC}, \mathrm{mm}$} & \multicolumn{2}{|c|}{$\mathrm{EB}, \%$} & \multicolumn{2}{|c|}{ DRIMP, T/mm } \\
\hline & & & & & $\begin{array}{l}\text { Inner } \\
\text { Cone }\end{array}$ & $\begin{array}{l}\text { Outer } \\
\text { Cone }\end{array}$ & $\begin{array}{l}\text { Inner } \\
\text { Cone }\end{array}$ & $\begin{array}{l}\text { Outer } \\
\text { Cone }\end{array}$ & $\begin{array}{l}\text { Inner } \\
\text { Cone }\end{array}$ & $\begin{array}{l}\text { Outer } \\
\text { Cone }\end{array}$ \\
\hline Lower Sirte & 640 & 22.4 & 84.6 & 7.6 & 0.18 & 0.45 & 14.7 & 12.9 & 57.4 & 24.0 \\
\hline Upper salt & 840 & 15.7 & 67.0 & 12.5 & 0.22 & 0.55 & 17.9 & 15.6 & 43.6 & 17.7 \\
\hline Mid anhydrite & 143 & 26.2 & 33.2 & 4.3 & 0.16 & 0.39 & 12.8 & 11.1 & 81.6 & 32.9 \\
\hline
\end{tabular}

Table 2. 8.5" PDC bit - rock type with estimated drilling parameters.

The bit took 84.6 hours to drill $640 \mathrm{ft}$ while the bit drilling in Lower Sirte rock (see Table 2), and the results indicated that the bit received damage in the early stage of the run. ROP has reached $33 \mathrm{ft} / \mathrm{hr}$ at depth of $12729 \mathrm{ft}$ during drilling in 100\% shale with WOB of $12 \mathrm{klbs}$ and RPM of 85 rpm (see Figs. $8 b$ and 8c). $29.6 \%$ of the inner cone effective blade (EB I) were in contact with rock (see Fig. 8d), and as a result, the wear evaluation index in the inner cone (DRIMP I) measured to $22 \mathrm{~T} / \mathrm{mm}$ as shown in Fig. 8e. While in the outer cone effective blades (EB O) was reduced to $25 \%$ and wear evaluation index in the outer cone (DRIMP O) was estimated to $9 \mathrm{~T} / \mathrm{mm}$ with no damage was estimated using the model equations in both cones as shown in Fig. 8f.

However, as the PDC bit penetrated into layers of 50\% limestone with $50 \%$ shale at $12736 \mathrm{ft}$, the ROP dropped because EB I was reduced to approximately $14.6 \%$ indicating the reductions on cutters width involved in drilling mechanism. In addition, the corresponding DRIMP I increased to $50.5 \mathrm{~T} / \mathrm{mm}$ as shown in Fig. 8e that cause a damage in the inner cone (L I) which calculated to $0.87 \mathrm{~mm}$ lost (see Fig. 8f). While in the outer cone DRIMP O increased to reach 20.6 T/mm with minor damage. As the rock structure was changed to Upper salt and rock strength reduces to $15.7 \mathrm{MPa}$ at $13360 \mathrm{ft}$ (see Table 2), the DRIMP reduced to 43.6 and 17.7 for inner and outer cones, respectively due to increment in EB of 18 and $15.6 \%$ in both cones as a function of DOC. Accordingly, the bit turns to be more aggressive and this is accompanied by an increment in the cutting area and rock removed. This is the case for both inner and outer cones. 
At $12750 \mathrm{ft}$ depth, the ROP of the bit decreased from 5.87 to $2.6 \mathrm{ft} / \mathrm{hr}$. Using the model equations, the L I was calculated to $1.58 \mathrm{~mm}$ lost at that depth as shown in Fig. 8f, where around $11 \%$ of EB I was involved in drilling as shown in Fig. 8d. On the other hand, the wear in the outer cone ( $\mathrm{L} \mathrm{O}$ ) was calculated to about $0.0045 \mathrm{~mm}$ lost (see Fig. 8f). The ROP is raised to $20 \mathrm{ft} / \mathrm{hr}$ as the bit started drilling into Upper salt rock at depth $13360 \mathrm{ft}$ where the rock strength is decreased to an average of $15.7 \mathrm{MPa}$ (see in the second row in Table 2). According to the model estimation, the EB I and EB O were $22 \%$ and $19 \%$, respectively.

At depth of $14200 \mathrm{ft}$ during drilling in Mid anhydrite with the corresponding rock strength of 26.2 MPa, the PDC bit struggled and ROP dropped to only $4.3 \mathrm{ft} / \mathrm{hr}$, while DRIMP jumped to reach high average values of $81.6 \mathrm{~T} / \mathrm{mm}$ in the inner cone compared to $33 \mathrm{~T} / \mathrm{mm}$ in the outer cone (see the third row in Table 2). Based on the above discussions and observations, keeping the bit in the hole with a sharp increase of DRIMP at the depth of over $14200 \mathrm{ft}$ may cause more severe damage to the inner cone, so the benefit of pulling the bit out is obvious at this depth.

Fig.8 Trend of drilling parameters along the depth of drilling and corresponding estimated drilling parameters for well number 1.

\subsection{Well Number 2}

The 16" PDC bit, designed with 6 blades - double rows and $16 \mathrm{~mm}$ cutter size was run at a depth of $2014 \mathrm{ft}$ to $3536 \mathrm{ft}$ to drill through Miocene, Oligocene, and Upper Eocene. The interval consists of limestone, clay, dolomite, sand, and marble. The bit was pulled out of the hole at the depth of $3536 \mathrm{ft}$ after severe damage at the outer cone and dulled for 1-4 as reported in the bit record.

Fig.9 Estimating of the stress of Miocene, Oligocene, and Upper Eocene.

\begin{tabular}{|c|c|c|c|c|c|c|c|c|c|c|c|}
\hline \multirow[b]{2}{*}{$\begin{array}{l}\text { Rock } \\
\text { Type }\end{array}$} & \multirow[b]{2}{*}{$\begin{array}{c}\text { Thick, } \\
\mathrm{ft}\end{array}$} & \multirow[b]{2}{*}{$\begin{array}{l}\text { UCS, } \\
\text { MPa }\end{array}$} & \multirow[b]{2}{*}{$\begin{array}{l}\text { Hardness } \\
\text { lb/sq.mm }\end{array}$} & \multirow[b]{2}{*}{$\begin{array}{c}\text { Time, } \\
\mathrm{hr}\end{array}$} & \multirow[b]{2}{*}{$\begin{array}{l}\mathrm{ROP}, \\
\mathrm{ft} / \mathrm{hr}\end{array}$} & \multicolumn{2}{|c|}{$\mathrm{DOC}, \mathrm{mm}$} & \multicolumn{2}{|c|}{$\mathrm{EB}, \%$} & \multicolumn{2}{|c|}{ DRIMP, T/mm } \\
\hline & & & & & & $\begin{array}{l}\text { Inner } \\
\text { Cone }\end{array}$ & $\begin{array}{l}\text { Outer } \\
\text { Cone }\end{array}$ & $\begin{array}{l}\text { Inner } \\
\text { Cone }\end{array}$ & $\begin{array}{l}\text { Outer } \\
\text { Cone }\end{array}$ & $\begin{array}{l}\text { Inner } \\
\text { Cone }\end{array}$ & $\begin{array}{l}\text { Outer } \\
\text { Cone }\end{array}$ \\
\hline Miocene & 646 & 20.6 & 18.9 & 25.0 & 25.7 & 0.51 & 0.83 & 28.9 & 60.4 & 9.8 & 17.5 \\
\hline Oligocene & 600 & 54.7 & 26.7 & 29.1 & 20.6 & 0.40 & 0.68 & 25.2 & 52.9 & 11.3 & 19.0 \\
\hline Upper Eocene & 276 & 31.3 & 100.4 & 30.7 & 8.9 & 0.24 & 0.40 & 19.3 & 40.8 & 31.8 & 41.1 \\
\hline
\end{tabular}

Table 3. 16" PDC bit - rock type with estimated drilling parameters.

The application consists of formations of Miocene, Oligocene, and Upper Eocene rocks with the UCS of 20.6, 54.7 and 31.3 MPa, respectively (see Table 3). In addition to the rock strength, 
the interval is heterogeneous as shown in Fig. 9 which create several challenges for the PDC to achieve a good ROP. The results of the model show that the PDC bit had a total wear flat height in the outer cone $\mathrm{L} \mathrm{O}$ greater than the actual wear after drilling $1522 \mathrm{ft}$ in $84.7 \mathrm{hr}$ (see Fig. 10).

The analysis of Table 3 reveals that the bit operated in good conditions and spent over 50 hours to drill nearly $1200 \mathrm{ft}$ including Miocene (646 ft) and Oligocene (600 ft). At the depth of 3260 $\mathrm{ft}$, WOB slightly increased as shown in Fig. $11 \mathrm{~b}$ where the bit started to require more energy to maintain the same ROP. This is accompanied by a drop of EB to 28.6 and $60 \%$, and that led DRIMP to raise to 5.8 and $12.3 \mathrm{~T} / \mathrm{mm}$ in both inner and outer cone respectively.

A sudden increase in WOB from 5.4 to 9 tone was applied to the bit to increase the ROP at $2187 \mathrm{ft}$ (see Fig. 11b), which resulted in a drop of 35\% in ROP (see Fig. 11a) due to formation cutting changed from $85 \%$ clay to $75 \%$ limestone as shown in Fig. 9. Accordingly, the bit outer cone showed a much stronger response as compared to the inner cone, DRIMP O was nearly doubled its value with damage; L O estimated to equal 1mm lost (refer to Fig. 11f). The bit design has a close influence on wear, DOC showed more response in the outer cone because of the cutting angle that resulted in an increase of cutting area. Based on that EB I of $25 \%$ out of total cutters width were involved in drilling (see Fig. 11d), while EB O was doubled of the inner as shown in Fig. 11d. This is corresponding to the DRIMP values obtained in both cones. By using the information of the Oligocene rock strength and rock hardness (see Table 3), the UCS was increased from 20.6 to $54.7 \mathrm{MPa}$; while ROP was decreased from 25.7 to $20.6 \mathrm{ft} / \mathrm{hr}$ with no extra wear recorded in both cones as shown in Fig. 11f. This has occurred as DRIMP increased to an average of $10 \%$ in both cones (i.e. from 9.8 to $11.3 \mathrm{~T} / \mathrm{mm}$ ).

Approximately 31 hours were spent to drill $276 \mathrm{ft}$ along Upper Eocene rock (see Table 3). However, the same period of time was taken to drill $600 \mathrm{ft}$ in Oligocene rock using the same PDC bit. Nevertheless, the formation strength was reduced from 54.7 to $31.3 \mathrm{MPa}$ as shown in Table 3. The closeness of this result may suggest that ROP is insensitive to rock hardness. The DOC and EB in both cones as shown in Table 3 decreased dramatically. This is related to ROP with a noticeable increment in DRIMP in both cones until the end of the 16 " section.

Wear measurement was made at every foot. However, it is logical to consider the wear when the bit was pulled out of the hole. To determine the bit dull condition, the wear model equations were used. L O was calculated to $5.3 \mathrm{~mm}$ as compared to $4.0 \mathrm{~mm}$ as an actual dull grading (see Fig. 11f). While the bit record presented that the bit is dulled to $1 \mathrm{~mm}$ lost in the inner cone as 
compared to $1.4 \mathrm{~mm}$ lost L I estimated by model equations. Fig. 10 shows the real photos of damage of the 16" PDC bit at the surface. The difference between the actual and the estimated wear as can be seen later in Fig.18 would be justified to the assumptions made in this model.

Fig.10 Damage of the 16" PDC bit.

Fig.11 Trend of drilling parameters along the depth of drilling and corresponding estimated drilling parameters for well number 2 .

\subsection{Well Number 3}

The 8.5" PDC bit contributed from 6 blades and $19 \mathrm{~mm}$ cutter size was used to drill $248 \mathrm{ft}$ into Upper Sirte formation with the average ROP of $11.8 \mathrm{ft} / \mathrm{hr}$ (see Table 4). The formation mainly consist of shale. Hydro - Guard mud, a clay free designed, was pumped into this section as a solution for reactive shale. The bit was pulled out of the hole at depth of $10673 \mathrm{ft}$ to check or change the bottom hole assembly and dulled in the bit record for 3-4.

Fig.12 Estimating of the Upper Sirte rocks strength.

\begin{tabular}{|c|c|c|c|c|c|c|c|c|c|}
\hline \multirow{2}{*}{$\begin{array}{l}\text { Top, } \\
\mathrm{ft}\end{array}$} & \multirow{2}{*}{$\begin{array}{l}\text { BTM, } \\
\text { ft }\end{array}$} & \multirow{2}{*}{$\begin{array}{c}\text { Thick, } \\
\text { ft }\end{array}$} & \multirow{2}{*}{$\begin{array}{l}\text { Rock } \\
\text { Type }\end{array}$} & \multirow{2}{*}{$\begin{array}{l}\mathrm{UCS} \\
\mathrm{MPa}\end{array}$} & \multirow{2}{*}{$\begin{array}{l}\text { Hardne } \\
\text { ss } \\
\mathrm{lb} / \mathrm{sq} \cdot \mathrm{m} \\
\mathrm{m}\end{array}$} & \multirow{2}{*}{$\begin{array}{c}\text { Time, } \\
\mathrm{hr}\end{array}$} & \multirow{2}{*}{$\begin{array}{l}\text { ROP, } \\
\mathrm{ft} / \mathrm{hr}\end{array}$} & \multicolumn{2}{|c|}{$\begin{array}{c}\text { DRIMP, } \\
\text { T/mm }\end{array}$} \\
\hline & & & & & & & & $\begin{array}{l}\text { Inner } \\
\text { Cone }\end{array}$ & $\begin{array}{l}\text { Outer } \\
\text { Cone }\end{array}$ \\
\hline 10425 & 10673 & 248 & Upper Sirte & 19.54 & 281.9 & 20.97 & 11.83 & 19.81 & 12.37 \\
\hline
\end{tabular}

Table 4. 8.5" Used PDC bit - rock type with estimated drilling parameters.

The PDC drilled till depth of $10629 \mathrm{ft}$ under controlled conditions, with stable DRIMP along an approximate of $70 \%$ interval of shale as shown in Fig. 12. The average ROP estimated to $93 \mathrm{ft} / \mathrm{hr}$ and DRIMP calculated to 15.1 and $9.4 \mathrm{~T} / \mathrm{mm}$ in the inner and outer cones, respectively as shown in Fig. 13e. During the section from 10629 to $10635 \mathrm{ft}$, and as the bit penetrated into traces of calcilutite rock (see Fig. 12), the driller decided to reduce WOB and increase RPM as shown in Figs. 13b and 13c. As a result, the average ROP declined to $87 \mathrm{ft} / \mathrm{hr}$ and DRIMP was suddenly raised to 24.5 and $15.2 \mathrm{~T} / \mathrm{mm}$ on both cones which reflect the poor bit efficiency with a drop in the effective blade in both inner and outer cones of 21.2 and $23 \%$, respectively (see Fig. 13d). At depth of $10658 \mathrm{ft}$, ROP dropped from 8.8 to $3.6 \mathrm{ft} / \mathrm{hr}$ with an increases in DRIMP because of the $15 \%$ increment of hardness from 18.3 to $22.5 \mathrm{~T} / \mathrm{mm}$ in inner cone and from 11.4 to $14 \mathrm{~T} / \mathrm{mm}$ in the outer (see Fig. 13e). 
The model has assumed that the bit is sharp, and hence the cutting angle, DOC, and wear in both cones were calculated as summarised in Table 5 .

\begin{tabular}{|c|c|c|c|}
\hline & Cutting angle $^{\mathbf{o}}$ & DOC, $\mathrm{mm}$ & $\mathrm{L}, \mathrm{mm}$ \\
\hline Inner cone & 43.1 & 0.422 & 0.340 \\
\hline Outer cone & 25.8 & 0.650 & 0.450 \\
\hline
\end{tabular}

Table 5. 8.5" Used PDC bit - cutting angle for inner and outer cones.

The results of Table 5 show that the outer cone is more responsive to cutting force caused by the radial distance to the bit centre, which was assumed constant for all cutters. The bit which used to drill in this section was a reused bit and maybe of partial integrity, i.e. cutter elements may be lost. However, the bit was evaluated at the surface, for 3-4 in the bit record, and concluded that the PDC has experienced more damage as compared to the results obtained from the model. This explained the difference obtained in the comparison between the estimated bit wear and the actual bit wear as shown later in Fig. 18.

Fig.13 Trend of drilling parameters along the depth of drilling and corresponding estimated drilling parameters for well number 3 .

\subsection{Well Number 4}

The 12.25" PDC bit which designed with 6 blades and $16 \mathrm{~mm}$ cutter size was used to drill in 12.25" hole. The bit drilled $112 \mathrm{ft}$ in Algata formation and $1588 \mathrm{ft}$ in Gir formation to the final planned depth of $6650 \mathrm{ft}$. The bit was pulled out from the hole at $6650 \mathrm{ft}$ and dulled for 3-X. (The actual dull grading of the outer cone is unknown).

Fig.14 Estimating of the Algata formation strength.

\begin{tabular}{|c|c|c|c|c|c|c|c|c|c|}
\hline \multirow{2}{*}{$\begin{array}{c}\text { Top, } \\
\mathrm{ft}\end{array}$} & \multirow{2}{*}{$\begin{array}{l}\text { BTM, } \\
\mathrm{ft}\end{array}$} & \multirow{2}{*}{$\begin{array}{c}\text { Thick, } \\
\text { ft }\end{array}$} & \multirow{2}{*}{$\begin{array}{l}\text { Rock } \\
\text { Type }\end{array}$} & \multirow{2}{*}{$\begin{array}{l}\text { UCS, } \\
\mathrm{MPa}\end{array}$} & \multirow{2}{*}{$\begin{array}{l}\text { Hardness } \\
\text { lb/sq.mm }\end{array}$} & \multirow{2}{*}{$\begin{array}{c}\text { Time, } \\
\text { hr }\end{array}$} & \multirow{2}{*}{$\begin{array}{l}\text { ROP, } \\
\mathrm{ft} / \mathrm{hr}\end{array}$} & \multicolumn{2}{|c|}{$\begin{array}{c}\text { DRIMP, } \\
\text { T/mm }\end{array}$} \\
\hline & & & & & & & & $\begin{array}{l}\text { Inner } \\
\text { Cone }\end{array}$ & $\begin{array}{l}\text { Outer } \\
\text { Cone }\end{array}$ \\
\hline 4950 & 5062 & 112 & Algata & 14.46 & 99.85 & 2.68 & 41.79 & 21.11 & 11.45 \\
\hline 5062 & 6650 & 1588 & Gir & 21.27 & 136.94 & 35.66 & 44.53 & 23.63 & 12.87 \\
\hline
\end{tabular}

Table 6. 12.25" PDC bit - rock type with estimated drilling parameters.

The selected 12.25" PDC drilled $1700 \mathrm{ft}$ in 38.3 hours through interbedded formation of calcilutite, dolomite, shale, and some layers of chert as shown in Fig.14. The results of the model show that the bit has pulled out in very good condition with no abrasive wear in both cones as shown in Fig. 15f. 
The high values of DOC are an indication of the impact wear resulted from sudden change of rock strength, and that can be seen in Fig. 15d for both inner and outer cones. This is evidence from the DOC which is reached to a value of approximately $3 \mathrm{~mm}$ for the outer cone. The bit is considered as efficient if the bit has low DRIMP and ROP is improved. The previous results for wells 1, 2 and 3 have demonstrated that the ROP should exhibit an inverse relationship with DRIMP, while in well 4, this is not the case and ROP is directly proportional to DRIMP in both inner and outer cones (see Figs. 15a, 15e, 16 and 17). This is clearly against the principles of the abrasive wear model. Additionally, considering the nature of the trend of ROP vs. DOC, ROP was decreased instead of rapidly increasing with DOC (see Figs. 16 and 17). These phenomena strengthen the idea that the wear which occurred on the 12.25" PDC is not abrasive wear but it is an impact wear. Accordingly, bit wear cannot be estimated by the model equations, and that can be clearly shown with poor comparison between the estimated and actual wear in both cones as summarised later in Fig.18.

Fig.15 Trend of drilling parameters along the depth of drilling and corresponding estimated drilling parameters for well number 4 .

Fig.16 Average. DOC - ROP and DRIMP (Inner Cone).

Fig.17 Average. DOC - ROP and DRIMP (Outer Cone).

Fig. 18 compares the obtained results of the calculated wear using the model and actual cutters wear recorded in the field. The model estimates the abrasive cutters wear in wells 1, 2 and 3 based on the assumptions made earlier for the development of the model. The good agreements are found between the estimated and the actual cutters wear for wells 1 and 2 . There is a considerable difference between the actual and the determined cutters wear in wells 3 and 4 . This is attributed to the case as the PDC bit in well 3 was not a new bit, so the bit may lost partially cutter elements during drilling in an offset well before rerun again to drill the 8.5" section in well 3. Also, the wear occurred to the bit drilled the 12.25 " section in well 4 was a result of impact wear and not because of abrasive wear.

Fig.18 Comparing the actual and the estimated bit wear for wells 1, 2, 3, and 4. 


\section{Conclusion}

The following conclusions can be drawn in this work:

1. The model presented in this paper is developed to aid PDC bit design and evaluation. The model also serves as a methodology to identify additional factors such as bit design and bit hydraulic that were not included in the past.

2. The concept of equal cutter wear and volume across the bit face reported in the literature is incomplete. This model does not consider the single cutter test, and accordingly, the model enables to estimate of the cutters wear in the inner and outer cones.

3. One of the most important outcomes of this work is the inclusion of the cutter width and the estimation of the effective cutters per blade which are involved in the drilling mechanism. This principle can account for designing a PDC bit with varied wear.

4. Effective blades, as well as DOC, are shown to be inversely proportional to the cutting angle.

5. The actual bit cutters wear for wells no 1 and 2 were in good agreement with the estimated wear by the model equations based on the model assumptions.

6. The actual bit cutters wear for wells no 3 and 4 exceeds the estimated bit wear. The bit ran in well 3 was a used bit, while; the damage occurred to bit drilled the 12.25" section in well 4 was due to impact wear (see Fig. 18).

7. This model has given satisfactory results only for sharp PDC bits and can only be applied to estimate the abrasive cutters wear. In addition, DRIMP changed in agreement with the bit life and is mainly depend on the bit geometry.

8. The proposed model in this paper is valid and can be applied for homogeneous and heterogeneous formation under the assumptions made in this work. Furthermore, the input data are standard and readily available or easy to obtain.

9. It would be most desirable if the model can be extended to apply to different shapes of cutters such as oval cutters. This is the ongoing research and will look into this in the future.

\section{Nomenclature}

$\mathrm{A}_{\mathrm{C}}=$ Cutting area of the cutter, $\mathrm{in}^{2}$ 
$\mathrm{A}_{\mathrm{w}}=$ Wearflat area, $\mathrm{in}^{2}$

$\mathrm{C}=$ Cutter width, in $^{2}$

$\mathrm{C}_{\mathrm{t}}=$ Total of cutters width, in

$\mathrm{D}_{\mathrm{b}}=$ Bit diameter, in

$\mathrm{D}_{\mathrm{C}}=$ Cutter diameter, in

DOC $=$ Depth of cut, in

DRIMP = Wear evaluation index, lb/in

DRIMP I = Wear evaluation index in inner cone, lb/in

DRIMP O = Wear evaluation index in outer cone, $\mathrm{lb} /$ in

$\mathrm{EB}=$ Effective blades, unitless

EB I = Effective blades in inner cone, unitless

$\mathrm{EB} \mathrm{O}=$ Effective blades in outer cone, unitless

$\mathrm{F}_{\mathrm{c}}=$ Cutting force, $\mathrm{lb}$

$\mathrm{g}$ = gage height, in

$\mathrm{G}=$ Cone height, in

$\mathrm{HP}=$ Bit hydraulic horsepower, $\mathrm{lb}$

HSI = Bit hydraulic efficiency, psi

$\mathrm{L}=$ Wear bit height, $\mathrm{mm}$

$\mathrm{L}_{\mathrm{b}}$ (inner) = Inner blade length, $\mathrm{mm}$

$\mathrm{L}_{\mathrm{b}}$ (outer) $=$ Outer blade length, $\mathrm{mm}$

$\mathrm{L} \mathrm{I}=$ Wear bit height in inner cone, $\mathrm{mm}$

$\mathrm{L} \mathrm{O}=$ Wear bit height in outer cone, $\mathrm{mm}$

$\mathrm{L}_{\mathrm{b}}=$ Blade length, in

MSE = Mechanical specific energy, psi

$\mathrm{MSE}_{\mathrm{H}}=$ Correlated mechanical specific energy for mud hydraulic, psi

MSE $_{\text {mod. }}=$ Modified mechanical specific energy, psi

$\mathrm{MSE}_{\mathrm{R}}=$ Correlated mechanical specific energy for rock hardness, psi

$\mathrm{MW}=$ Mud weight, lb/gal

$\mathrm{N}_{\mathrm{b}}=$ Number of blades, unitless

$\mathrm{N}_{\mathrm{c}}=$ Number of cutters, unitless

$\mathrm{P}=$ Bit pressure drop, psi

$\mathrm{PR}=$ Penetration rate, $\mathrm{ft} / \mathrm{hr}$

$\mathrm{Q}=$ Flow rate, gpm 
$\mathrm{R}=$ Distance from cutter to bit centre, in

$\mathrm{R}_{\mathrm{i}}=$ Inner radial distance, in

$\mathrm{R}_{\mathrm{o}}=$ Outer radial distance, in

$\mathrm{ROP}=$ Rate of penetration, $\mathrm{ft} / \mathrm{hr}$

$\mathrm{RPM}=$ Rotary speed, $\mathrm{rpm}$

$\mathrm{r}_{\mathrm{b}}=$ Bit radius, in

$\mathrm{r}_{\mathrm{c}}=$ Cutter radius, in

$r_{i}=$ Inner cone radius, in

$\mathrm{r}_{\mathrm{o}}=$ Outer cone radius, in

$\mathrm{T}=$ Torque, $\mathrm{lb}_{\mathrm{m}}-$ in

$\mathrm{TFA}=$ Bit total flow area, $\mathrm{in}^{2}$

$\mathrm{T}_{\text {mod. }}=$ Torque, $\mathrm{lb}_{\mathrm{f}}-$ in

UCS = Unconfined compressional strength, psi

$\left(\mathrm{V}_{\mathrm{r}}\right)_{\mathrm{a}}=$ Actual volume of rock removed, $\mathrm{in}^{3}$

$\left(\mathrm{V}_{\mathrm{r}}\right)_{\mathrm{t}}=$ Theoretical volume of rock removed, $\mathrm{in}^{3}$

WOB $=$ Weight on bit, $\mathrm{lb}_{m}$

$\delta=$ Hardness or the cutting force per unit area, psi

$\varnothing=$ Cutting angle, ${ }^{\circ}$

$\sigma^{\prime}=$ Formation stress, psi

$\mu=$ Rock friction, unitless

\section{Acknowledgment}

The financial support from ministry of higher education in Libya is gratefully acknowledged.

\section{References}

Alkaragoolee, M. Y. 2018. Hybrid Modelling and Optimisation of Oil Well Drillstrings. (Doctoral dissertation, University of Bradford).

Abbas, R. \& Hassanpour, A. 2018. Evaluating the Wear of Polycrystalline Diamond Compact Drill Bit Cutters using Indentation and Scratch Tests. ARO-The Scientific Journal of Koya University, 6, 46-54.

Bourgoyne, A. T., Millheim, K. K., Chenevert, M. E. \& Young, F. S. 1986. Applied drilling engineering. SPE Textbook Series, Vol. 2. Society of Petroleum Engineers, Richardson, TX.

Brandon, B., Cerkovnik, J., Koskie, E., Bayoud, B., Colston, F., Clayton, R., Anderson, M., Hollister, K., Senger, J. \& Niemi, R. 1992. First revision to the IADC fixed cutter dull grading system. SPE/IADC Drilling Conference, 18-21 February, New Orleans, Louisiana. Society of Petroleum Engineers. 
Chen, S., Grosz, G., Anderle, S., Arfele, R. and Xun, K. 2014. The role of 3D rock chips and cutting area shapes in PDC bit-design optimization. Abu Dhabi International Petroleum Exhibition and Conference, Society of Petroleum Engineers.

De Reynal, M. 2011. Method to determine rock properties from drilling logs. Google Patents. US8082104B2.

Detournay, E. 1993. Method of determining the drilling conditions associated with the drilling of a formation with a drag bit. Google Patents. US5216917A.

Detournay, E. and Defourny, P. 1992. A phenomenological model for the drilling action of drag bits. International journal of rock mechanics and mining sciences \& geomechanics abstracts, Elsevier, 13-23.

Detournay, E., Richard, T. \& Shepherd, M. 2008. Drilling response of drag bits: Theory and experiment. International Journal of Rock Mechanics and Mining Sciences, 45, 13471360.

Doshvarpassand, S., Richard, T. \& Mostofi, M. 2017. Effect of groove geometry and cutting edge in rock cutting. Journal of Petroleum Science and Engineering, 151, 1-12.

Ersoy, A. \& Waller, M. 1995. Wear characteristics of PDC pin and hybrid core bits in rock drilling. Wear, 188, 150-165.

Gerbaud, L., Menand, S. and Sellami, H. 2006. PDC bits: all comes from the cutter rock interaction. IADC/SPE Drilling Conference, Feb 2006, Miami, United States.

Glowka, D. A. 1985. Implications of thermal wear phenomena for PDC bit design and operation. September, Las Vegas, Nevada. Society of Petroleum Engineers.

Glowka, D. A. 1987. Development of a method for predicting the performance and wear of PDC drill bits. Thecnical report, Sandia national laboratories.

Gouda, G. M., Maestrami, M., Abu Saif, M. A., El-Moghrebi, S. S., Dahab, A. S. A. H. and Farehat, M. S. A. 2011. A Mathematical Model To Compute The Pdc Cutter Wear Value To Terminate PDC Bit Run. SPE Middle East Oil and Gas Show and Conference.

Gray, K. E. 1967. Some rock mechanics aspects of petroleum engineering. In The 9th US Symposium on Rock Mechanics (USRMS). American Rock Mechanics Association.

Hankins, D., Salehi, S. and Karbalaei Saleh, F. 2015. An Integrated Approach for Drilling Optimization Using Advanced Drilling Optimizer. Journal of Petroleum Engineering. Volume 2015, Article ID 281276, 12 pages.

Hareland, G. and Rampersad, P. 1994. Drag-bit model including wear. SPE Latin America/Caribbean Petroleum Engineering Conference.

Hibbs, J. L. E. and Flom, D. G. 1978. Diamond Compact Cutter Studies for Geothermal Bit Design. Journal of Pressure Vessel Technology, 100, 406-416.

Huang, Z., Ma, Y., Li, Q. and Xie, D. 2017. Geometry and force modeling, and mechanical properties study of polycrystalline diamond compact bit under wearing condition based on numerical analysis. Advances in Mechanical Engineering, 9(6).

Jogi, P. N. and Zoeller, W. A. 1995. Method for evaluating formations and bit conditions. Google Patents. US5415030A.

Jones, M. L. 1990. Drill bit having improved cutter configuration. Google Patents. US4913247A.

Kerr, C. J. 1988. PDC drill bit design and field application evolution. Journal of petroleum technology, 40, 327-332.

Kuru, E. 1990. Effects of Rock/Cutter Friction on PDC Bit Drilling Performance: An Experimental and Theoretical Study. Dissertation, Louisiana State University and Agricultural \& Mechanical College.

Kuru, E. \& Wojtanowsicz, A. 1988. A method for detecting in-situ PDC bit dull and lithology change. SPE/IADC Drilling Conference. Society of Petroleum Engineers. 
Liu, Z., Marland, C., Li, D. and Samuel, R.. 2014. An analytical model coupled with data analytics to estimate PDC bit wear. In SPE Latin America and Caribbean Petroleum Engineering Conference. Society of Petroleum Engineers.

Maurer, W. 1966. The state of rock mechanics knowledge in drilling. The 8th US Symposium on Rock Mechanics (USRMS). American Rock Mechanics Association.

Mensa-Wilmot, G., Soza, R. and Hudson, K. 2003. Advanced cutting structure improves PDC bit performance in hard rock drilling environments. Society of Petroleum Engineers.

Mohan, K., Adil, F. and Samuel, R. 2009. Tracking drilling efficiency using hydro-mechanical specific energy. SPE/IADC Drilling Conference and Exhibition. Society of Petroleum Engineers.

Patil, P. and Teodoriu, C. 2013. Analysis of bit rock interaction during stick slip vibration using PDC cuttting force model. DGMK/OeGEW Spring meeting 2013 of the exploration and production department (Germany).

Pryhorovska, T. O. 2017. Study on rock reaction force depending on PDC cutter placement. Machining Science and Technology, 21, 37-66.

Ragan, D. M. 2009. Structural geology: an introduction to geometrical techniques, Cambridge University Press.

Sinor, L. and Warren, T. 1987. Drag bit wear model. SPE Annual Technical Conference and Exhibition, 27-30 September, Dallas, Texas. Society of Petroleum Engineers.

Sinor, L. A., Hansen, W. R., Dykstra, M. W., Cooley, C. H. \& Tibbitts, G. A. 2001. Drill bits with controlled cutter loading and depth of cut. Google Patents. US6298930B1.

Spread, M. 2017. Drilling Forum [Online]. Available: https://my-spread.com/.

Teale, R. 1965. The concept of specific energy in rock drilling. Elsevier, 57-73.

Tian, J., Fu, C., Yang, L., Yang, Z., Pang, X., Li, Y., Zhu, Y. and Liu, G. 2015. The wear analysis model of drill bit cutting element with torsion vibration. Advances in Mechanical Engineering, 7(1), p.254026.

Tulu, I. and Heasley, K. 2009. Calibration of 3D cutter-rock model with single cutter tests. 43rd US Rock Mechanics Symposium \& 4th US-Canada Rock Mechanics Symposium. American Rock Mechanics Association.

Tveit, Ø. S. and Berg, P. V. 2016. Model for evaluating drilling efficiency based on the concept of Mechanical Specific Energy, (Master's thesis, NTNU).

Van Quickelberghe, F., Dagrain, F., Tshibangu, J. P. \& Richard, T. 2006. A new procedure to analyse the wear of cutting elements. Taylor and Francis, London.

Warren, T. \& Sinor, A. Drag bit performance modeling.1987. SPE Annual Technical Conference and Exhibition. Society of Petroleum Engineers.

Wang, X., Wang, Z., Wang, D. and Chai, L. 2018. A novel method for measuring and analyzing the interaction between drill bit and rock. Measurement, 121, 344-354.

Wojtanowicz, A. and Kuru, E. 1993. Mathematical modeling of PDC bit drilling process based on a single-cutter mechanics. Journal of Energy Resources Technology, 115, 247-256.

Yahiaoui, M., Gerbaud, L., Paris, J.-Y., Delbe, K., Denape, J. \& Dourfaye, A. 2011. Analytical and experimental study on PDC drill bits quality. 3rd Europeen Conference on Tribology, Jun 2011, Vienne, Austria. pp.475.

Yang, H., Zhao, H. \& Kottapurath, S. 2019. Real-time bit wear prediction using mud logger data with mathematical approaches. Journal of Petroleum Exploration and Production Technology, 1-8.

Ziaja, M. B. \& Miska, S. 1982. Mathematical model of the diamond-bit drilling process and its practical application. Society of Petroleum Engineers Journal, 22, 911-922. 